Check for updates

Cite this: New J. Chem., 2018, 42, 10481

Received 25th January 2018, Accepted 19th March 2018

DOI: 10.1039/c8nj00450a

rsc.li/njc

\section{Various types of non-covalent interactions contributing towards crystal packing of halogenated diphospha-dicarbaborane with an open pentagonal belt $\dagger$}

\author{
Josef Holub, ${ }^{a}$ Zdeňka Rủžičková, ${ }^{b}$ Pavel Hobza, (D) *c Jindřich Fanfrlík, (D) *c \\ Drahomír Hnyk (D) *a and Aleš Rưžička*b
}

\begin{abstract}
We have prepared 3-Cl-10-I-nido-7,8,9,11- $\mathrm{P}_{2} \mathrm{C}_{2} \mathrm{~B}_{7} \mathrm{H}_{7}$ by the reaction of 3-Cl-nido-7,8,9,11- $\mathrm{P}_{2} \mathrm{C}_{2} \mathrm{~B}_{7} \mathrm{H}_{8}$ with $\mathrm{I}_{2}$ in the presence of $\mathrm{AlCl}_{3}$. The product was obtained in a yield of $49 \%$ and was characterized by NMR spectroscopy and X-ray crystallography. Quantum chemical calculations have demonstrated that the crystal structure is stabilized by hydrogen, dihydrogen and pnictogen bonds.
\end{abstract}

Innerly and/or outerly substituted boron cluster hydrides (heteroboranes) of various architectures are known for various types of non-covalent intermolecular interactions and thus serve as good models for the evaluation and mutual comparison of various types of hydrogen, dihydrogen (diH), halogen (X), chalcogen, pnictogen (Pn) or even tetrel bonds. ${ }^{1,2}$ The neutral nido- $\mathrm{B}_{7} \mathrm{P}_{2}[\mathrm{C}(\mathrm{R})]_{2} \mathrm{H}_{7}$ cage with an open $\mathrm{P}_{2} \mathrm{CBC}$ pentagonal belt can be formally obtained from nido $-\mathrm{B}_{11} \mathrm{H}_{11}{ }^{4-}$ (nido- $\mathrm{B}_{11} \mathrm{H}_{14}{ }^{-}$ exists) ${ }^{3}$ by replacing four $\mathrm{BH}$ vertices with two tetrel and Pn vertices. Miscellaneous dicarba dipnictogen nido eleven-vertex heteroboranes have been prepared by reacting arachno-4,5$\mathrm{C}_{2} \mathrm{~B}_{7} \mathrm{H}_{13}$ with $\mathrm{PCl}_{3}, \mathrm{AsCl}_{3}$ and $\mathrm{SbCl}_{3} \cdot{ }^{4-6}$ The crystal structures of 3-Cl-nido-7,8,9,11- $\mathrm{P}_{2} \mathrm{C}_{2} \mathrm{~B}_{7} \mathrm{H}_{8}$ (1), 3-I-nido-7,8,9,11- $\mathrm{As}_{2} \mathrm{C}_{2} \mathrm{~B}_{7} \mathrm{H}_{8}$ (2) and nido-7,8,9,11- $\mathrm{Sb}_{2} \mathrm{C}_{2} \mathrm{~B}_{7} \mathrm{H}_{9}$ (3) compounds are already known. ${ }^{4-6}$ The crystal packing of 3 is governed by Pn-bonds. ${ }^{6}$ In contrast to 3 , it has not been possible to record the singlecrystal X-ray data of the parent nido-7,8,9,11- $\mathrm{P}_{2} \mathrm{C}_{2} \mathrm{~B}_{7} \mathrm{H}_{9}$ and nido-7,8,9,11- $-\mathrm{As}_{2} \mathrm{C}_{2} \mathrm{~B}_{7} \mathrm{H}_{9}$ in sufficient quality. Interestingly, it is feasible to determine the structure of single-crystal halogenated compounds 1 and 2, revealing a supramolecular architecture mainly resulting from extensive Pn-bonding. ${ }^{4-6}$ In order to

\footnotetext{
${ }^{a}$ Institute of Inorganic Chemistry of the Czech Academy of Sciences, 25068 Husinec-Řež, Czech Republic. E-mail: hnyk@iic.cas.cz

${ }^{b}$ Department of General and Inorganic Chemistry, Faculty of Chemical Technology, University of Pardubice, Studentská 573, 53210 Pardubice, Czech Republic. E-mail: ales.ruzicka@upce.cz

${ }^{c}$ Institute of Organic Chemistry and Biochemistry of the Czech Academy of Sciences, Flemingovo nam. 2, 16610 Prague 6, Czech Republic.

E-mail: hobza@uochb.cas.cz, fanfrlik@uochb.cas.cz

$\dagger$ Electronic supplementary information (ESI) available. CCDC 1819146. For ESI and crystallographic data in CIF or other electronic format see DOI: 10.1039/c8nj00450a
}

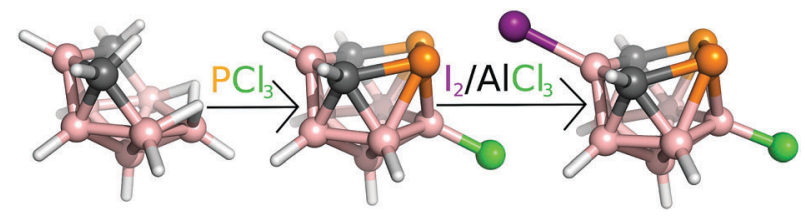

Fig. 1 A simplified reaction scheme.

proceed in the examination of the non-covalent interactions of nido-heteroboranes, we attempted to iodinate $\mathbf{1}$ (Fig. 1) by the reaction with elemental iodine in the presence of aluminum trichloride (details in ESI $\dagger$ ). The resulting 3-Cl-10-I-nido-7,8,9,11$\mathrm{P}_{2} \mathrm{C}_{2} \mathrm{~B}_{7} \mathrm{H}_{7}$ (4) was obtained in a moderate yield of $49 \%$ and was characterized in solution in terms of multinuclear NMR spectroscopy (Table 1).

In the crystal structure of 4 (Fig. 2), four molecules have been found in the unit cell. The structure of the cage of $\mathbf{4}$ is essentially the same as found for $\mathbf{1}^{4}$ except for the very slight shortening of the $\mathrm{B}(10)-\mathrm{C}(9 / 11)$ bonds inside the open $\mathrm{P}_{2} \mathrm{CBC}$ pentagonal belt caused by the substitution of the $\mathrm{B}(10)$ atom by the heavy iodine. In fact, there are only two examples of a similar structural pattern in the Cambridge Structural Database, i.e. dicarba-closo-dodecaborane-1,2-diyl-1,2-bis(diisopropylamino)diphosphines, ${ }^{9}$ but these are heavily distorted with no option of a serious structural comparison.

Table 1 NMR results for $\mathbf{4}^{a}$

\begin{tabular}{llrlrl}
\hline & $\mathrm{B}(1)$ & $\mathrm{B}(3)$ & $\mathrm{B}(2,4)$ & $\mathrm{B}(10)^{b}$ & $\mathrm{~B}(5,6)$ \\
\hline GIAO & -29.3 & 2.5 & -2.0 & 5.9 & 3.5 \\
Exp. & -31.2 & -0.7 & -1.9 & -14.7 & 0.3
\end{tabular}

${ }^{a}$ All in ppm with respect to $\mathrm{BF}_{3} \cdot \mathrm{OEt}_{2}$. Atomic numbering is shown in Fig. $2{ }^{b}$ The discrepancy between the calculated and experimental chemical shift results from the neglect of the effect of spin-orbit (SO) coupling on the overall shielding, which is not taken into account in the GIAO-MP2 scheme. However, it has been shown that due to iodine being terminally bonded to a boron atom within a neutral boron cluster, SO coupling increases the contribution of this B atom towards overall shielding by about $20 \mathrm{ppm},{ }^{7,8}$ which would considerably improve the fit in the present case. 


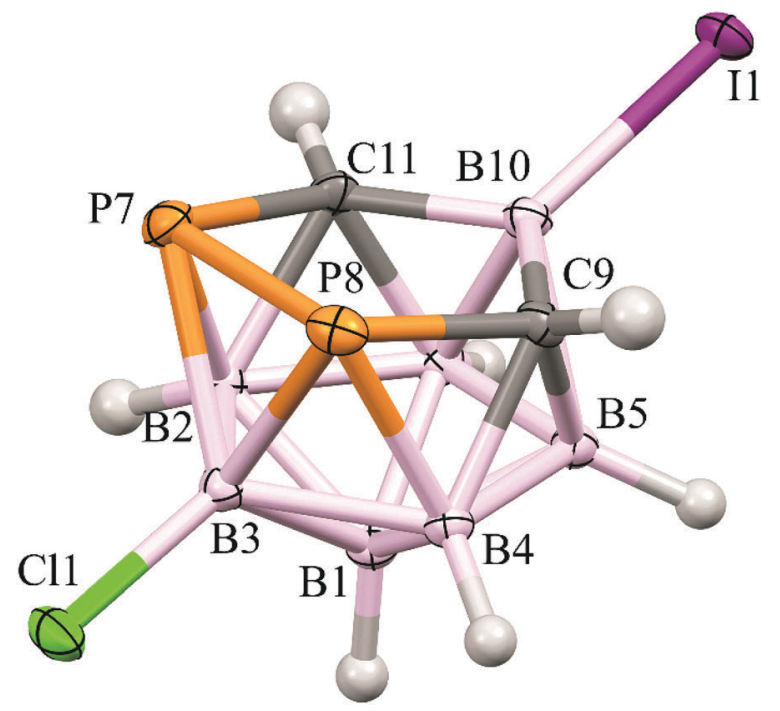

Fig. 2 The molecular structure (ORTEP 50\% probability level) and atomic numbering of 4 . The selected interatomic distances $[\AA]$ are: I1-B10 2.184(2), Cl1-B3 1.786(2), B2-C11 1.730(3), B2-P7 2.053(2), B3-P8 2.1117(19), B3-P7 2.113(2), B4-C9 1.732(2), B4-P8 2.0516(18), B5-C9 1.715(3), B6-C11 1.715(2), C9-B10 1.608(2), C9-P8 1.8681(17), C9-H9 0.91(3), B10-C11 1.604(3), C11-P7 1.8706(19) and P8-P7 2.1970(6). For all the distances and other structural characteristics, see Table S2 (ESI $\dagger$ ).

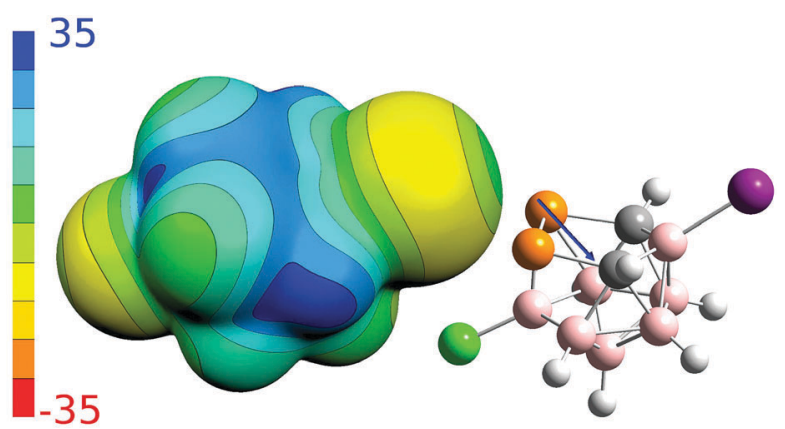

Fig. 3 The computed electrostatic potential (ESP) surface for compound 4 The color range of the ESP in $\mathrm{kcal} \mathrm{mol}^{-1}$. The direction of the dipole moment is shown as an arrow derived at the HF/cc-pVTZ level.

To better understand non-covalent interactions of $\mathbf{4}$, we computed its ESP potential (Fig. 3) and compared it with other recently studied analogous compounds, 1-3. Compound 1 has only one highly positive $\sigma$-hole located on the P vertices. The other expected $\sigma$-holes of 1 could not be defined on the $\mathrm{P}$ vertices due to the more positive neighboring $\mathrm{CH}$ vertices. The $\mathrm{Sb}$ and As vertices of $\mathbf{2}$ and $\mathbf{3}$ have more positive ESP surfaces than the $\mathrm{CH}$ vertices. Both molecules thus have three well-defined $\sigma$-holes on the Pn atoms. From this point of view, the ESP surface of 4 is thus analogous to 2 and 3. Compound 4 has three $\sigma$-holes located on $\mathrm{P}$ atoms with the same magnitude $\left(V_{\mathrm{S}, \mathrm{max}}\right)$ of $31.5 \mathrm{kcal} \mathrm{mol}^{-1}$. The $\mathrm{P}$ vertices of 4 have even more positive ESP values than the $\mathrm{CH}$ vertices. The ESP surface on top of the $\mathrm{CH}$ vertices has the value of $28.2 \mathrm{kcal} \mathrm{mol}^{-1}$. Besides the $\sigma$-holes located on $\mathrm{P}$ atoms, the 4 compound also has $\sigma$-holes on the $\mathrm{X}$ atoms. While the I atom has a positive $\sigma$-hole
Table 2 The magnitudes of $\sigma$-holes $\left(V_{\mathrm{S} \text {, max }}\right)$ on the surfaces of group $V$ and VII atoms and dipole moments $(\mu)$ computed at the HF/cc-pVDZ level

\begin{tabular}{lll}
\hline & $V_{\mathrm{s}, \max } / \mathrm{kcal} \mathrm{mol}^{-1}$ & \\
\cline { 2 - 3 } Compound & Group V atoms & Group VII atoms \\
\hline $\mathbf{1}$ & $25.4^{6}$ & $-3.1^{6}$ \\
$\mathbf{2}$ & $32.2 ; 2 \times 29.0^{6}$ & $8.2^{6}$ \\
$\mathbf{4}$ & $1 \times 42.7 ; 2 \times 25.7^{6}$ & - \\
\hline
\end{tabular}

with the $V_{\mathrm{S} \text {,max }}$ value of $6.8 \mathrm{kcal} \mathrm{mol}^{-1}$, the $\mathrm{Cl}$ atom only has a relative $\sigma$-hole (i.e. the top of the $\mathrm{Cl}$ atom is less negative than its belt but the $V_{\mathrm{S} \text {, max }}$ value is negative). The $\mathbf{4}$ compound can thus form Pn-, H- and X-bonds, the last of which are, however, less probable due to the lower $V_{\mathrm{S} \text {, max }}$ values on the $\mathrm{X}$ atoms (Table 2). The most negative ESP surface of 4 is on the negative belt on the I and $\mathrm{Cl}$ atoms (the magnitudes of -15.1 and $-12.3 \mathrm{kcal} \mathrm{mol}^{-1}$, respectively).

Finally, we have studied pairwise interactions in the crystal structure of 4 and compared them with those of 1, 2 and 3. Highly-accurate MP2/CBS interaction energy $(\Delta E)$ values are summarized in Table 3 (see also Fig. 4). The A $\cdots$ B motif is the most stable motif of 4 . The motif can be described as two symmetrical $\mathrm{P}_{2} \cdots \mathrm{I}$ Pn-bonds. Since the Pn-bond is quite long (3.8 $\mathrm{A})$, it could also be seen as a nonspecific dispersion contact with an optimal dipole-dipole arrangement. The $\Delta E$ value of $-9.5 \mathrm{kcal} \mathrm{mol}^{-1}$ is very large, considerably more negative than the most negative bonding motifs of 1 and 2 (the $\Delta E$ of about

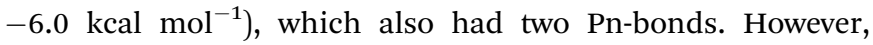
considering that the A $\cdots$ B motif of 4 has two Pn-bonds, they are weaker than the Pn-bonds of $\mathbf{3}$. Compound $\mathbf{3}$ has a binding motif that is exclusively formed by a single Pn-bond and has the $\Delta E$ value of $-6.5 \mathrm{kcal} \mathrm{mol}^{-1}{ }^{6}$

The A $\cdots \mathrm{C}$ motif, formed by two symmetrical $\mathrm{C}-\mathrm{H} \cdots \mathrm{I}-\mathrm{B}$ $\mathrm{H}$-bonds, has $\Delta E$ of $-6.5 \mathrm{kcal} \mathrm{mol}^{-1}$. The $\mathrm{H}$-bond is again rather long ( $3.2 \AA)$. The third most stable motif is A $\cdots \mathrm{D}$ with $\Delta E$ of $-6.1 \mathrm{kcal} \mathrm{mol}^{-1}$. It is formed by the $\mathrm{C}-\mathrm{H} \cdots \mathrm{H}-\mathrm{B}$ dihydrogen bond and the $\mathrm{C}-\mathrm{H} \cdots \mathrm{I}-\mathrm{B} \mathrm{H}$-bond. The $\mathrm{C}-\mathrm{H} \cdots \mathrm{H}-\mathrm{B}$ diH-bond is the only contact in the crystal structure of $\mathbf{4}$ with the length below the sum of van der Waals radii $(2.9 \AA$ between the $\mathrm{H}$ and

Table 3 Interaction energies $(\Delta E)$ in $\mathrm{kcal} \mathrm{mol}^{-1}$

\begin{tabular}{|c|c|c|}
\hline & Interaction & $\mathrm{MP} 2.5 / \mathrm{CCSD}(\mathrm{T})$ \\
\hline \multicolumn{3}{|c|}{ 3-Cl-nido-7,8,9,11- $\mathrm{P}_{2} \mathrm{C}_{2} \mathrm{~B}_{7} \mathrm{H}_{8}$ (1) } \\
\hline $\mathrm{A} \cdot \mathrm{B}$ & $2 \times$ Pn-bond & $-5.93^{6} /-6.10^{6}$ \\
\hline \multicolumn{3}{|c|}{ 3-I-nido-7,8,9,11- $\mathrm{As}_{2} \mathrm{C}_{2} \mathrm{~B}_{7} \mathrm{H}_{8}$ (2) } \\
\hline $\mathrm{A} \cdots \mathrm{B}$ & $2 \times$ Pn-bond & $-5.98^{6}$ \\
\hline A $\cdots C$ & $2 \times$ Pn-bond & $-5.67^{6}$ \\
\hline \multicolumn{3}{|c|}{ nido-7,8,9,11- $\mathrm{Sb}_{2} \mathrm{C}_{2} \mathrm{~B}_{7} \mathrm{H}_{9}$ (3) } \\
\hline A $\cdots B$ & $2 \times$ Pn-bond, $\mathrm{HH}$-bond & $-6.80^{6} /-7.05^{6}$ \\
\hline A $\cdots C$ & Single Pn-bond & $-6.22^{6} /-6.46^{6}$ \\
\hline \multicolumn{3}{|c|}{ 3-Cl-10-I-nido-7,8,9,11- $\mathrm{P}_{2} \mathrm{C}_{2} \mathrm{~B}_{7} \mathrm{H}_{7}$ (4) } \\
\hline $\mathrm{A} \cdot \cdots \mathrm{B}$ & $2 \times$ Pn-bond & -9.5 \\
\hline A $\cdots C$ & $2 \times$ H-bond & -6.5 \\
\hline A $\cdots D$ & diH and $\mathrm{H}$-bonds & -6.1 \\
\hline $\mathrm{A} \cdot \mathrm{E}$ & Stacking & -4.8 \\
\hline
\end{tabular}



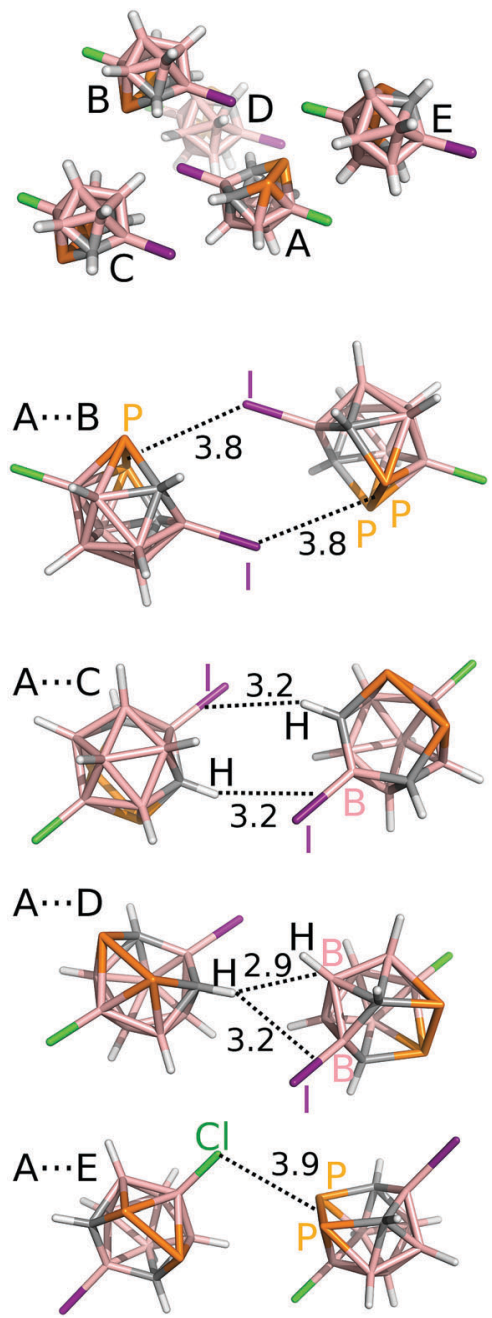

Fig. 4 The most significant interaction motifs from the crystal structure of 3-Cl-10-I-nido-7,8,9,11- $\mathrm{P}_{2} \mathrm{C}_{2} \mathrm{~B}_{7} \mathrm{H}_{7}$ (4). The distances are in $\AA$. The positions of the $\mathrm{H}$ atoms have been optimized at the DFT-D3/BLYP/DZVP level. ${ }^{10}$

the center of the $\mathrm{B}-\mathrm{H}$ bond; $\mathrm{H} \cdots \mathrm{H}$ and $\mathrm{H} \cdots \mathrm{B}$ distances of 2.3 and $3.0 \AA$, respectively). The A $\cdots$ E motif also has all contacts much higher than the sum of the van der Waals radii (e.g. the $\mathrm{P}_{2} \cdots \mathrm{Cl}$ Pn bond of $3.9 \AA$ ).

In summary, compound 4 (3-Cl-10-I-nido-7,8,9,11- $\mathrm{P}_{2} \mathrm{C}_{2} \mathrm{~B}_{7} \mathrm{H}_{7}$ ) was prepared by reacting 3-Cl-nido-7,8,9,11- $\mathrm{P}_{2} \mathrm{C}_{2} \mathrm{~B}_{7} \mathrm{H}_{8}$ with elemental iodine in the presence of aluminum trichloride. Its molecular structure has been characterized by NMR spectroscopy, X-ray crystallography and $a b$ initio computations. Apart from $\mathrm{B}(10)$ there is a good accord between the experimental and computed ${ }^{11} \mathrm{~B}$ chemical shifts. It is the spin-orbit coupling that is responsible for such a disagreement related to $\mathrm{B}(10)$. The combination of $\mathrm{Pn}-$, diH and $\mathrm{H}$-bonds turned out to be a driving force for the crystal packing as revealed by quantum chemical computations.

\section{Conflicts of interest}

There are no conflicts to declare.

\section{Acknowledgements}

This work was supported by the research project RVO 61388963 of the Czech Academy of Sciences. We acknowledge the financial support of the Czech Science Foundation (17-08045S).

\section{Notes and references}

1 (a) G. Cavall, P. Metrangolo, R. Milani, T. Pilati, A. Primagi, G. Ransani and G. Terraneo, Chem. Rev., 2016, 116, 2478; (b) S. Scheiner, Acc. Chem. Res., 2013, 46, 280; (c) A. Bundhun, P. Ramasami, J. S. Murray and P. Politzer, J. Mol. Model., 2013, 19, 2739; (d) A. Bauza, T. Mooibroek and A. Frontera, ChemPhysChem, 2015, 16, 2496.

2 R. Sedlak, J. Fanfrlík, A. Pecina, D. Hnyk, P. Hobza and M. Lepšík, Boron - the Fifth Element, in Challenges and Advances in Computational Chemistry and Physics, ed. D. Hnyk and M. McKee, Springer, Heidelberg, New York, Dordrecht and London, ch. 9, vol. 20, 2015.

3 For the structure of $\mathrm{B}_{11} \mathrm{H}_{14}{ }^{-}$with three hydrogen bridges, see: J. Fritchie, Inorg. Chem., 1967, 6, 1199-1203.

4 J. Holub, T. Jelínek, D. Hnyk, Z. Plzák, I. Císařová, M. Bakardjiev and B. Štíbr, Chem. - Eur. J., 2001, 7, 1546.

5 L. Mikulášek, B. Grüner, I. Císařová and B. Štíbr, Dalton Trans., 2003, 1332.

6 J. Holub, P. Melichar, Z. Růžičková, J. Vrána, D. A. Wann, J. Fanfrlík, D. Hnyk and A. Růžička, Dalton Trans., 2017, 46, 13714.

7 J. Macháček, J. Plešek, J. Holub, D. Hnyk, V. Všetečka, I. Císařová, M. Kaupp and B. Štíbr, Dalton Trans., 2006, 1024.

8 B. Štíbr, J. Holub, M. Bakardjiev, P. D. Lane, M. L. McKee, D. A. Wann and D. Hnyk, Inorg. Chem., 2016, 56, 852.

9 A. Kreienbrink, M. B. Sarosi, E. G. Rys, P. Lonnecke and E. Hey-Hawkins, Angew. Chem., Int. Ed., 2011, 50, 4701.

10 J. Hostaš and J. Řezáč, J. Chem. Theory Comput., 2017, 13, 3575 . 